\title{
YouTube as a Source of Patient Information on Myofascial Pain Syndrome
}

\section{YouTube als Quelle für Patienteninformationen beim Myofaszialen Schmerzsyndrom}

Author

Ayça Uran Şan

Affiliation

Gaziler Physical Therapy and Rehabilitation Training and Research Hospital, Department of Physical Medicine and Rehabilitation, Ankara, Turkey

Key words

Myofascial Pain Syndrome, Youtube, Information

Schlüsselwörter

Myofasziales Schmerzsyndrom, Youtube, Information

published online $\quad 10.11 .2021$

Bibliography

Akt Rheumatol 2021; 46: 577-582

DOI $10.1055 / a-1652-1351$

ISSN 0341-051X

(c) 2021. Thieme. All rights reserved.

Georg Thieme Verlag, Rüdigerstraße 14,

70469 Stuttgart, Germany

Correspondence

Dr. Ayça Uran Şan

Ankara Gaziler Physical Therapy and Rehabilitation Training and Research Hospital

Department of Physical Medicine and Rehabilitation

Üniversiteler Mahallesi

Lodumlu Yolu

29 Ekim Sokak, No:1

Bilkent Çankaya/Ankara

06800 Ankara

Turkey

Tel.: + 90/312/29110 00, Fax: +90/312/2911009

dr.uran@hotmail.com

\section{ABSTRACT}

Introduction Myofascial pain syndrome is a local disorder characterised by pathological myofascial constrictions and trigger points. One of the most popular sources of internet-based information for patients is YouTube, which provides a lot of videos related to myofascial pain syndrome, making it one of the top clinical conditions searched for on the site. This study aimed to examine the quality of the YouTube video content on myofascial pain syndrome.
Method This study was designed as a cross-sectional study and used the YouTube video sharing website as the main source of data. A search of the relevant videos was performed by entering the words "myofascial pain syndrome" in June 2021. Video characteristics were recorded, and the quality of the videos was assessed according to the Journal of the American Medical Association (JAMA) benchmark criteria, the DISCERN Scale and the Global Quality Scale.

Results A total of 322 videos were evaluated, 186 of which were subjected to analysis after applying the inclusion/exclusion criteria. The videos were categorised into groups, with 10 (5.4\%) falling into the high-quality group, 16 (8.6\%) into the intermediate quality group, and $160(86 \%)$ into the low-quality group. The findings from the study showed that the most popular videos, the highest number of video likes and the highest number of video views were in the intermediate group, while the high-quality group had the lowest popularity level, number of video likes and number of video views $(p<0.05)$.

Conclusions Although there are videos with high-quality content on YouTube offering guidance to patients about the disease, it is important to keep in mind that inaccurate and deficient information about the disease may also be present on this platform.

\section{ZUSAMMENFASSUNG}

Einleitung Ein myofasziales Schmerzsyndrom ist eine mit pathologischen myofaszialen Verkürzungen und Triggerpunkten verbundene lokale Störung. Eine der populärsten internetbasierten Informationsquellen für Patienten ist YouTube. Hier gibt es viele Videos über das myofasziale Schmerzsyndrom, was es zu einem der meistgesuchten Krankheitsbilder auf dieser Website macht. Die vorliegende Studie hat sich das Ziel gesetzt, die Qualität des Inhaltes von Videos auf YouTube über das myofasziale Schmerzsyndrom zu untersuchen.

Methode Diese Studie wurde als eine Querschnittsstudie erstellt und benutzt die Video-Sharing-Website Youtube als Hauptdatenquelle. Im Juni 2021 wurde über die Eingabe der Begriffe "myofasziales Schmerzsyndrom" eine Suche auf YouTube durchgeführt. Die Videoeigenschaften wurden dokumentiert und die Qualität der Videos nach den Benchmarkkriterien des Journal of the American Medical Association (JAMA), der DISCERN-Skala und der Global Quality Scale, bewertet. 
Ergebnisse 322 Videos wurden bewertet, wovon 186 nach Anwendung der Ein- und Ausschlusskriterien analysiert wurden. Die Videos wurden in Gruppen eingeteilt, wobei 10 $(5,4 \%)$ in die Qualitätsgruppe hoch, $16(8,6 \%)$ in die Qualitätsgruppe intermediär und 160 (86\%) in die Qualitätsgruppe niedrig fielen. Die Ergebnisse zeigten, dass die beliebtesten Videos, die höchste Anzahl von Video-Likes und die höchste Anzahl von Videoaufrufen in der intermediär Gruppe vorhanden waren, während die Qualitätsgruppe hoch die geringste Popularität, Anzahl von Video-Likes und Anzahl von Videoaufrufen aufwies $(P<0,05)$.

Schlussfolgerung Obwohl es auf YouTube Videos mit qualitativ hochwertigem Inhalt gibt, die Patienten über die Krankheit aufklären, ist es wichtig zu bedenken, dass auf dieser Plattform auch ungenaue und mangelhafte Informationen über die Krankheit vorhanden sind.

\section{Introduction}

Myofascial pain syndrome is a local disorder that is characterized by pathological myofascial constrictions and trigger points [1]. With this syndrome, painful and pathological taut band formations usually occur in the musculoskeletal system, causing severe pain, autonomic phenomena and regional tenderness in patients [2]. Myofascial pain can have various clinical manifestations, including referred pain, radiculopathy, or major joint pain, and it can significantly reduce the quality of life of patients [3]. The diagnosis of the myofascial pain syndrome is based on the palpation of trigger points located in a discrete band within a muscle [3]. There are many treatment options for myofascial pain syndrome, including analgesics, muscle relaxant medications, antidepressants, local injections, dry needle therapy, stretching exercises, myofascial release techniques, physical therapy modalities, and manual therapy [4].

Today, with the rise in the use of the internet, patients have started to turn to it to receive medical information. In a study by Yoon et al. involving the participation of 17704 adults, it was reported that approximately $40 \%$ of participants used the internet for health information [5]. YouTube is one of the leading internet resources used by patients for medical purposes. Since YouTube is a worldwide video sharing site and provides free access to video content, it is considered an alternative way to disseminate health-related information [6]. However, the advertisements and non-scientific content that can appear on YouTube has raised concerns about the quality and accuracy of the contents of the videos [6]. This study aims to examine the quality of the myofascial pain syndrome-related contents of YouTube videos. To the best of our knowledge, this is the first study to evaluate the quality of YouTube videos for myofascial pain syndrome. The findings from this study shall serve as a guide for taking the proper steps to provide reliable and scientifically accurate video contents about this syndrome.

\section{Material and Methods}

The data for this cross-sectional study were collected from the YouTube video sharing website. For the selection of videos, a search, inputting "myofascial pain syndrome", was conducted on the YouTube website in June 2021. The options "video" and "sort by number of views" were selected as filters. All the URLs returned from the search were recorded on an Excel sheet and assessed by a researcher with expert experience in myofascial pain syndrome. From the total of 322 videos assessed, 186 were included in the study after applying the inclusion and exclusion criteria. To be included in the study, the videos had to be English and have content related to myofascial pain syndrome. Duplicate videos, inaccessible videos, videos with content unrelated to myofascial pain syndrome, and videos in a language other than English were excluded from the study.

The duration of the video ( in seconds), the interval of time from when the video was first uploaded (in days), number of total views, total number of comments, number of comments per year, number of likes and dislikes, video like ratio [like/(like + dislike) $\times 100$ ], and video view ratio [number of views/days] were recorded as part of the evaluation procedure. Video power index (VPI) [like ratio $\times$ view ratio/100], which was used to determine the popularity level of the video, was also calculated for each video.

The content of the videos was categorized as 'general information', 'patient experience', 'symptoms' 'physical examination findings', 'medical treatment options', 'exercise treatment', 'myofascial releasing techniques', 'injection therapy', 'other treatment modalities', and 'preventive information'. The sources of the videos were categorized as follows: 'physician', 'non physician healthcare worker', 'trainer', 'medical massage therapist', 'patient', and 'health-related website'. Finally, the quality of the videos were assessed using the Journal of the American Medical Association (JAMA) benchmark criteria, the DISCERN Scale, and the Global Quality Scale.

The JAMA benchmark criteria, which was used in this study to evaluate the credibility and accuracy of the information presented on the YouTube videos, includes four criteria, 'authorship', 'attribution', disclosure', and 'currency', with 1 point assigned for the presence of each criterion [7]. In the JAMA benchmark criteria, it is being investigated whether the authors, their affiliations, contributors, references for all content, dates of the content, relevant credentials, any advertising, copyright information, underwriting, sponsorship , potential conflicts of interest, commercial funding arrangements are specified [7]. A score of 0 indicates poor credibility and accuracy, while a score of 4 indicates strong credibility and accuracy [7]. The DISCERN Scale is an instrument which consists of questions on the quality of informations about treatment options, reliability and quality of the overall content [8]. It has a score range of $0-80$ points, with higher scores indicating advanced level of quality [8]. The Global Quality Scale (GQS) is a 5-point instrument which consists of criteria that examine the quality of the content, the rate of benefit to the patients, the level of flow and the inclusion of important information [9]. Scores of 1-2 points on this scale indicate low quality, 3 points indicate intermediate quality, and $4-5$ points indicate high quality [9]. Since the present study did not include any animal or human participants and the videos used as the sources of data were accessible to everyone, the study did not require 
ethics committee approval. There are similar studies with the same protocol in the literature $[6,10]$.

Statistical analyses were performed using version 22.0 SPSS software (IBM Corp., Armonk, NY, USA). The Shapiro-Wilk test was used to determine whether the obtained parameters conformed to a normal distribution. For the descriptive analyses of the data collected, the mean \pm standard deviation (SD) was calculated. Kruskal-Wallis test was used to compare the continuous variables. To investigate the associations between non-normally distributed, or ordinal variables, the correlation coefficients ( $r$ ) and their significance $(p)$ were calculated using the Spearman test. A probability value of $p<0.05$ was considered statistically significant.

\section{Results}

In the initial evaluation of the 322 videos returned from the search criteria used on YouTube, $18.32 \%(n=59)$ were unrelated topics, $10.86 \%(n=35)$ were duplicate videos, and $10.86 \%(n=35)$ were in a language other than English. After excluding these videos, a total of 186 videos remained. In terms of the named sources of the videos, $27.5 \%(n=51)$ were uploaded by a physician, $11.8 \%(n=22)$ by a non-physician health care professional, $11.8 \%(n=22)$ by a trainer, $8.6 \%(n=16)$ by a massage therapist, $11.8 \%(n=22)$ by a patient, and $28.5 \%(n=53)$ by health-related websites.

A total of 98 videos (52.7\%) were categorized as general information, 12 videos (6.5\%) as patient experience, 4 videos (2.1\%) as symptoms (local or radicular pain, muscle tenderness, sweating, numbness, paresthesia etc.) , 9 videos (4.8\%) as physical examination findings, 1 video ( $0.5 \%$ ) as medical treatment options, 6 vide-

- Table 1 General characteristics of the videos.

\begin{tabular}{|l|c|}
\hline & Mean (SD) \\
\hline Video Duration (sec) & $671.40(141.07)$ \\
\hline Number of Video Views & $51563.12(17147.73)$ \\
\hline Number of Video Likes & $591.68(272.62)$ \\
\hline Number of Video Dislikes & $18.26(6.71)$ \\
\hline Number of Comments & $30.51(11.39)$ \\
\hline
\end{tabular}

os (3.2\%) as exercise treatment, 27 videos (14.6\%) as myofascial releasing techniques, 6 videos (3.2\%) as injection therapy, 22 videos $(11.8 \%)$ as other treatment modalities, and 1 video $(0.6 \%)$ as preventative information.

The average duration of the videos was 671.40 (SD: 141.07) seconds; the average interval of time from when the video was first uploaded was 1492.85 (SD: 84.27) days. The average number of total views was 51563.12 (SD: 17147.73); the average total number of comments was 30.51 (SD: 11.39) ( $\triangleright$ Table 1); the average number of comments per year was 10.04 (SD: 3.60); the average number of likes was 591.68 (SD: 272.62 ), and the average number of dislikes was 18.26 (SD: 6.71); the average video like ratio was 76.85 (SD: 2.53); the average video view ratio was 43.33 (SD: 19.51); and finally, the average VPI was 40.12 (SD: 18.35).

The mean JAMA score was $1.40 \pm 0.05$, the mean total Global Quality Scale score was $1.54 \pm 0.06$, and the mean total Discern Scale score was $20.87 \pm 0.59$. Based on the Global Quality Scale score, 10 (5.4\%) videos were categorized under the high-quality group, 16 $(8.6 \%)$ videos were categorized under the intermediate quality group, and 160 (86\%) videos were categorized under the lowquality group. The categorization of the video qualities according to their sources is shown in $>$ Table 2.

The results from this study revealed that the videos with longer duration included more accurate, reliable, and credible information, as indicated by the positive, intermediate level of correlation between the video duration and JAMA ( $p<0.001$, r: 0.452), DISCERN $(p<0.001, r: 0.495)$ and Global Quality Scale scores $(p<0.001$, $r: 0.460)$. It was also found that the videos with higher quality content related to the treatment of myofascial pain syndrome had a lower number of views, as indicated by the statistically weak, negative correlation between the number of total video views and the DISCERN-treatment quality subgroup (p: 0.033, r: -0.157).

Analysis of the video sources revealed that the most viewed videos by the viewers were the videos whose source was physicians, with the average total number being 120085.04 (SD: 4.03) views. Similarly, physician-based videos were the most commented on videos, with an average total number of 53.17 (SD: 264.75) comments. The most liked videos were those whose source was trainers, with an average total number of 1123.27(SD: 3578.33) likes. The videos with the highest mean VPI score were those by nonphysician health-care workers (152.80, SD: 627.91). The average

- Table 2 The categorization of the video qualities according to their sources, $\mathrm{n}(\%)$.

\begin{tabular}{|c|c|c|c|c|}
\hline Video source & Low quality & Intermediate quality & High quality & Total \\
\hline Physician & 31 (19.4) & $10(62.5)$ & $10(100)$ & 51 \\
\hline Non-physician health care professional & $20(12.5)$ & $2(12.5)$ & $0(0)$ & 22 \\
\hline Trainer & $21(13.1)$ & $1(6.2)$ & $0(0)$ & 22 \\
\hline Massage therapist & $16(10.0)$ & $0(0)$ & $0(0)$ & 16 \\
\hline Patient & $22(13.8)$ & $0(0)$ & $0(0)$ & 22 \\
\hline Health-related websites & $50(31.2)$ & $3(18.8)$ & $0(0)$ & 53 \\
\hline
\end{tabular}


- Table 3 Comparison of video characteristics according to quality levels.

\begin{tabular}{|c|c|c|c|c|c|c|}
\hline Video quality & $\begin{array}{l}\text { JAMA score a } \\
\text { mean (SD) }\end{array}$ & $\begin{array}{l}\text { DISCERN } \\
\text { score }^{a} \\
\text { mean (SD) }\end{array}$ & $\begin{array}{l}\text { View ratio } \\
\text { mean }^{b} \text { (SD) }\end{array}$ & $\begin{array}{l}\text { Number of likes a } \\
\text { mean (SD) }\end{array}$ & $\begin{array}{l}\text { Number of } \\
\text { dislikes }^{b} \\
\text { mean (SD) }\end{array}$ & $\begin{array}{l}\text { Number of } \\
\text { comments }^{\mathrm{C}} \text { per } \\
\text { year mean (SD) }\end{array}$ \\
\hline Low quality & $1.21(0.03)$ & $18.31(0.24)$ & $33.51(20.64)$ & 265.67 (119.69) & $10.03(4.44)$ & $6.22(2.41)$ \\
\hline Intermediate quality & $2.31(0.15)$ & $29.87(1.10)$ & $165.68(90.90)$ & $4163.62(2864.23)$ & $110.68(61.29)$ & $47.83(33.36)$ \\
\hline High quality & $3.10(0.10)$ & $47.5(3.20)$ & $4.84(2.94)$ & 92.80 (67.79) & $2.20(1.27)$ & $10.67(9.02)$ \\
\hline
\end{tabular}

JAMA, DISCERN Scale, and Global Quality Scale scores were highest in the videos whose source was physicians [(1.98, SD: 0.81) (27.5, SD: 12.24) (2.25, SD: 1.18 ), respectively].

The videos were categorized into low-quality group, intermediate-quality group, and high-quality group according to the total Global Quality Scale. A statistically significant differences was found between the groups in terms of the total number of comments ( $p$ : $0.024)$, number of video likes $(p<0.001)$, total number of video views (p: 0.009) and VPI (p: 0.001). The highest VPI scores were in the intermediate-quality group (160.79, SD: 355.48), while the lowest VPI scores were in the high-quality group (4.71, SD: 9.1). It was further found that the highest number of comments were in the intermediate-quality group (195.31, SD: 478.80), and that the number of video likes was highest in the intermediate-quality group (4163.62, SD: 11456.95) and lowest in the high-quality group (92.80, SD: 214.38). The average number of video views was highest in the intermediate-quality group (299915.12, SD: 5.67) and lowest in the high-quality group $(3701.90$, SD: 6105,48) ( Table 3).

\section{Discussion}

With the steady development of technology and the high frequency use of computers, tablets, and smart phones, internet use has dramatically risen throughout the world. Individuals have started to prefer the internet to obtain information in all fields, including the field of health, where patients turn to it to access general information about diseases and to learn about possible symptoms, diagnosis, and treatment methods. Various studies have revealed that $80 \%$ of internet users have received medical information online [11-13]. One of the most popular sources of information for patients on the internet is YouTube. Research has shown that one new video is uploaded to the system every minute on YouTube, which is watched by approximately 2 billion people daily, and that internet users in average spend about 15 minutes per day on this site [13-15]. The results of three studies by Fox et al. showed that 75 percent of internet users were influenced by the information on the internet when deciding which treatment to choose for their diseases, and that internet platforms like YouTube have the potential to serve as an important tool for sharing and disseminating medical information among users [13, 16-19]. However, the minimal regulating mechanisms and guidelines for the video content uploaded to YouTube and the increasing amount of anecdotal infor- mation on the platform have raised doubts about the quality of the video content in terms of the accuracy and reliability of the information provided [13].

Although there are many videos related to myofascial pain syndrome on Youtube; there were no studies found on the quality and reliability of the videos about myofascial pain syndrome in the literature review conducted as part of this study.

In the present study, categorization of the videos related to myofascial pain syndrome on YouTube according to the quality level, as determined by the total Global Scale score, showed that most of the videos were of low quality. The high-quality group had the lowest number of videos. Similarly, in a study by Gokcen et al., the quality of the disc herniation information presented on YouTube was evaluated as low quality [20]. A study by Zengin et al. involving an examination of the educational quality of YouTube videos on musculoskeletal ultrasound showed that $40.1 \%$ of the videos were of low quality [21]. In contrast, in a study by Kocyiğit et al., which aimed to determine the quality of videos on the link between COVID-19 and rheumatic disease, it was reported that $41.4 \%$ of the 46 videos (n:19) were high quality [22].

Although it was determined in the present study that the most viewed and commented on videos were physician-sourced videos, the videos with the highest number of likes were those made by trainers, and that the most popular videos, with the highest VPI scores, were videos made by non- physician healthcare workers. Various conclusions can be drawn from this. In a study by Erdem et al. that evaluates the quality of information for kyphosis on YouTube, it was reported that the academic-based videos had significantly lower VPI scores compared to those of other sources, save for the medical and patient categories [23]. Yörükoğlu et al. showed in their study examining the accuracy of YouTube videos on osteoporosis that health professional-sourced videos received the most likes, while the videos by official institutions had the least number of likes [24]. In another study by Koçyiğit et al. that investigated the level of benefit of YouTube videos on lumbar disc herniation exercises, it was found that the videos uploaded by trainers had the highest number of views and comments per day [25].

According to the JAMA, DISCERN Scale, and Global Quality Scale score results of the present study, the highest-quality videos on YouTube regarding myofascial pain syndrome were the physician-sourced videos. Similarly, Erdem et al. stated in their study evaluating the quality and accuracy of YouTube videos on kyphosis that academic videos had significantly higher JAMA and Global 
Quality Scale scores compared to those of other video sources [23]. In a study by Kuru et al. aimed at determining the quality of YouTube videos on rotator cuff tears, it was revealed that the DISCERN scores were significantly higher in physician-sourced videos compared to those of non-physician-sourced videos; the same study also reported that there was a statistically significant difference between the JAMA scores of physician-sourced and non-physician-sourced videos [26].

The findings from the present study showed that the most popular videos, with the highest VPI scores, were in the intermediate quality group; additionally the highest number of video likes and the highest number of video views were in the intermediate group. Conversely, the high quality group had the lowest popularity level, number of video likes, and number of video views. From these findings, it is important to keep in mind that the most popular videos on the internet may not always include the highest quality of information. In a study by Kocyiğit et al. to determine the quality level of YouTube videos on secukinumab treatment, it was revealed that there was no significant difference between the low-, intermediate- and high-quality groups in terms of number of views, comments per day, and likes, the results of which led them to conclude that the parameters of number of views, likes, and comments per day should not be construed as an indicator of quality for videos on YouTube [27]. A study by Zengin et al. analyzing information presented on YouTube videos about the side effects of biologic therapy found that there was no significant difference between the low-quality, intermediate-quality, and high-quality groups in terms of the number of views, VPI scores, and number of likes on these videos [28].

The present study had two limitations important to point out. First, only English language videos were included, meaning that video content in other languages could have altered the findings. Second, the Global Quality Scale, which is a subjective assessment scale, was used to evaluate video quality.

\section{Conclusion}

Since myofascial pain syndrome is a common disorder and impairs the quality of life of individuals, it is extremely important that patients receive accurate and reliable information from credible sources for the management of the disease. Professional sources should perhaps also improve their attractiveness for Internet users and adapt to the target group in the process. Although there is high-quality content available on YouTube to guide patients about the disease, it is important to keep in mind that incorrect and unreliable information may also be included on this platform. Therefore, it is recommended that clinicians provide detailed information to patients about their diseases and inform them about scientific sources from which they can obtain reliable information.

\section{Conflict of Interest}

The author declares that she has no conflict of interest.
[1] Cao QW, Peng BG, Wang L et al. Expert consensus on the diagnosis and treatment of myofascial pain syndrome. World J Clin Cases 2021; 9: 2077-2089

[2] Travell JG, Simons LS. Myofascial pain and dysfunction. The Trigger Point Manual: Upper Half of Body. $2^{\text {nd }}$ edition. Lippincott, Williams \& Wilkins; Baltimore: 1999

[3] Gerwin RD. Diagnosis of myofascial pain syndrome. Physical Medicine and Rehabilitation Clinics Of North America 2014; 25: 341-355

[4] Desai M], Saini V, Saini S. Myofascial pain syndrome: A treatment review. Pain and Therapy 2013; 2: 21-36

[5] Yoon H, Jang Y, Vaughan PW et al. Older adults' internet use for health information: Digital divide by race/ethnicity and socioeconomic status. Journal of Applied Gerontology: The Official Journal of the Southern Gerontological Society 2020; 39: 105-110

[6] Kocyigit BF, Nacitarhan V, Koca TT et al. YouTube as a source of patient information for ankylosing spondylitis exercises. Clinical Rheumatology 2019; 38: 1747-1751

[7] Silberg WM, Lundberg GD, Musacchio RA. Assessing, controlling, and assuring the quality of medical information on the Internet: Caveant lector et viewor - Let the reader and viewer beware. Jama 1997; 277: 1244-1245

[8] Charnock D, Shepperd S, Needham G et al. DISCERN: An instrument for judging the quality of written consumer health information on treatment choices. Journal Of Epidemiology and Community Health 1999; 53: 105-111

[9] Bernard A, Langille M, Hughes S et al. A systematic review of patient inflammatory bowel disease information resources on the World Wide Web. The American Journal of Gastroenterology 2007; 102: 20702077

[10] Tolu S, Yurdakul OV, Basaran B et al. English-language videos on YouTube as a source of information on self-administer subcutaneous anti-tumour necrosis factor agent injections. Rheumatology International 2018; 38: 1285-1292

[11] Atkinson NL, Saperstein SL, Pleis ]. Using the internet for health-related activities: Findings from a national probability sample. J Med Internet Res 2009; 11: 4

[12] Rutten L], Squiers L, Hesse B. Cancer-related information seeking: Hints from the 2003 Health Information National Trends Survey (HINTS). Journal of Health Communication 2006; 11: 147-156

[13] Madathil KC, Rivera-Rodriguez AJ, Greenstein JS et al. Healthcare information on YouTube: A systematic review. Health Informatics Journal 2015; 21: 173-194

[14] YouTube at five- 2 bn views a day. London. (Internet). (cited 2021 June 28). Available from: http://news.bbc.co.uk/2/hi/technology/8676380. stm/

[15] YouTube statistics. California. (Internet). (cited 2021 June 28). Available from: http://www.viralblog.com/research-cases/youtubestatistics/

[16] Fox S. Online health search 2006. Pew Internet \& American Life Project; Washington, DC: 2006

[17] Fox S, Purcell K. Chronic disease and the internet. Pew Internet \& American Life Project; Washington, DC: 2010

[18] Fox S, Jones S. The social life of health information (Americans' pursuit of health takes place within a widening network of both online and offline sources). Pew Internet\&American Life Project; California Healtcare Foundation; Washington, DC: 2009 
[19] Fox S. The engaged e-patient population: people turn to the Internet for health information when the stakes are high and the connection fast. 2008; (Internet). (cited 2021 June 28). Available from: http:// www.pewinternet.org/Reports/2008/The-EngagedEpatient-Population.aspx

[20] Gokcen HB, Gumussuyu G. A Quality analysis of disc herniation videos on YouTube. World Neurosurgery 2019; 124: 799-804

[21] Zengin O, Onder ME. Educational quality of YouTube videos on musculoskeletal ultrasound. Clin Rheumatol 2021; 40: 4243-4251

[22] Kocyigit BF, Akaltun MS, Sahin AR. YouTube as a source of information on COVID-19 and rheumatic disease link. Clinical Rheumatology 2020; 39: 2049-2054

[23] Erdem MN, Karaca S. Evaluating the accuracy and quality of the information in kyphosis videos shared on YouTube. Spine 2018; 43: 1334-1339
[24] Yörükoğlu AÇ, Uzun SU. Accuracy and reliability of YouTube videos as an information source for osteoporosis. J Ankara Univ Fac Med 2020; 73: 9-13

[25] Kocyigit BF, Okyay RA, Akaltun MS. YouTube as a source of e health: Is it beneficial for lumbar disc herniation exercises? J PMR Sci 2020; 23 : 217-23.

[26] Kuru T, Erken HY. Evaluation of the quality and reliability of YouTube videos on rotator cuff tears. Cureus 2020; 12: 6852

[27] Kocyigit BF, Akaltun MS. Does YouTube provide high quality information? Assessment of secukinumab videos. Rheumatology International 2019; 39: 1263-1268

[28] Zengin O, Onder ME. YouTube for information about side effects of biologic therapy: A social media analysis. International Journal of Rheumatic Diseases 2020; 23: 1645-1650 